\title{
15th Annual Congress of the European Society for Photodynamic Therapy in Barcelona, Spain, February 12-13th 2016
}

\author{
Lasse R. Braathen · Colin A. Morton · Rolf-Markus Szeimies
}

Received: May 26, 2016 / Published online: June 17, 2016

(C) The Author(s) 2016. This article is published with open access at Springerlink.com

\section{ABSTRACT}

We provide a summary of the presentations made at the recent Euro-PDT annual Congress. Presentations covered developments in topical photodynamic therapy (PDT) pertaining to dermatological applications. Recognizing the high prevalence and chronicity of actinic keratosis, one of the approved indications for PDT, there were recommendations to pursue field therapy to treat clinical and preclinical lesions. A separate section was reserved to review the strong evidence for the use of daylight PDT for actinic keratosis and experience of use of this well tolerated form of PDT was reported from several countries. Several presentations covered the

Enhanced content To view enhanced content for this article go to http://www.medengine.com/Redeem/ FAD4F0607FBE5C3C.

L. R. Braathen $(\bowtie)$

Dermatology Bern, Bern, Switzerland

e-mail: lasse.r.braathen@bluewin.ch

C. A. Morton

Department of Dermatology, Stirling Community

Hospital, Stirling, UK

Rolf-MarkusSzeimies

Department of Dermatology and Allergology,

Knappschaftskrankenhaus Recklinghausen,

Recklinghausen, Germany remaining approved uses of topical PDT, Bowen's disease and basal cell carcinomas, as well as considering its role in so far unapproved indications including photorejuvenation.

Funding: Galderma.

Keywords: Actinic keratosis; Basal cell carcinomas; Bowen's disease; Daylight PDT; Euro-PDT; Field therapy; Photodynamic therapy; Photorejuvenation

\section{INTRODUCTION}

This year the conference was held again in Barcelona, Spain. Around 250 participants from Europe, but also Brazil, Canada and Singapore attended the two-day meeting which this year mainly focused on the new development and introduction of daylight-mediated photodynamic therapy (DL-PDT) in dermatologic therapy.

\section{DAY 1}

In his introductory speech, the President of EURO-PDT, Prof. Lasse Braathen, Berne, Switzerland, briefly reviewed the journey from the experimental beginning of PDT to its current 


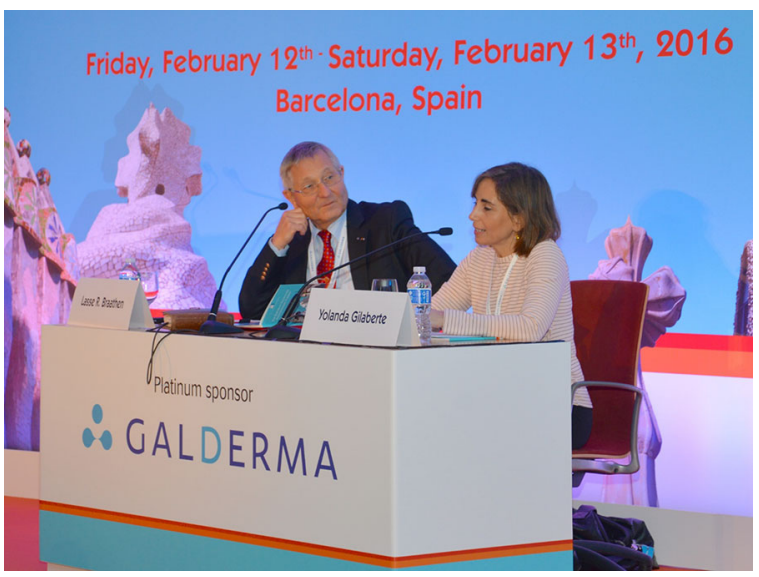

Fig. 1 Prof. Lasse Braathen, Berne Switzerland, President EURO-PDT and Prof. Yolanda Gilaberte, Huesca, Spain, Congress President, during the Open Ceremony of the 15th Annual Congress of EURO-PDT

place as an accepted treatment procedure not only for the treatment of non-melanoma skin cancer (NMSC) including lymphomas but also for other indications like acne, skin rejuvenation, skin infections and other inflammatory disorders. Prof. Yolanda Gilaberte, Huesca, Spain, the Congress President, reflected on the tradition of the Annual EURO-PDT Meeting that permits researchers and clinicians from different countries get the opportunity not only to learn but also to interact and exchange knowledge and experience in the field of PDT (Fig. 1).

\section{Plenary Session I: Epidemiology, Diagnosis and Consensus}

The first plenary session focused on the epidemiology, diagnosis and consensus activities in the field of NMSC. Dr. Maria Fargnoli from L'Aquila presented a large Italian survey conducted in dermatology outpatient departments on prevalence and risk factors of actinic keratoses (AK). The three highest independent risk factors were age, previous NMSC, and living in Southern Italy; protective factors were $\mathrm{BMI} \geq 25.0$, regular sunscreen use and lower educational level. Dr. Maria Teresa Fernández Figueras from Barcelona, Spain gave an excellent summary of her recent research on the "differentiated pathway" of development of AK to invasive squamous cell carcinoma (SCC) which underlines the need of an early treatment even of thin AK. Prof. Piergiacomo Calzavara-Pinton from Brescia, Italy reported on the current project to update existing clinical guidelines of AK by combination of both new treatment options like DL-PDT or ingenol mebutate (IMB) and the preparation of a three-round Delphi panel. This approach will allow the development a treatment algorithm which will be published soon.

\section{Plenary Session II: AK Lesion Versus Field Therapy Skin Preparation}

In the second plenary session, choosing between lesional and field therapy for AK was discussed. Prof. Thomas Dirschka from Wuppertal Germany focused on real life situations in dermatologic practice and pointed out that complete lesion clearance is rarely achieved and, therefore, our treatment goal should be reduction of number of AK lesions with a field-directed approach. In the same series of talks, pretreatment was also reviewed. Keratolytic therapy in patients with AK prior to methyl-aminolevulinate PDT (MAL-PDT) with salicylic acid cream (10\%) or urea cream (40\%) was significantly effective in respect of higher lesion response rates but also associated with a higher rate of local reactions. Other preparation methods [curettage, microdermabrasion with abrasive pads, microneedling or ablative fractionated laser systems (AFXL)] presented by Prof. Merete Hædersdal from Copenhagen, Denmark, 
confirmed these observations. In another study run by Prof. Gerber from Düsseldorf, Germany, pretreatment of actinic field cancerization with AFXL or microneedling followed by MAL-PDT led to increased protoporphyrin IX concentration and better outcome.

\section{Plenary Session III: Efficacy Data}

The third plenary session and main part of the congress focused on the recent developments of DL-PDT. Regarding efficacy data, first results on comparative trials were reported. Dr. Mariateresa Rossi from Brescia, Italy presented an interesting study comparing IMB with MAL-PDT on two symmetrical contralateral areas. Complete remission rates at 3 months were slightly better for conventional MAL-PDT, with local skin reactions more severe and time to healing longer with IMB. Since there are no direct comparative trials with diclofenac sodium/hyaluronic acid (DHA) and DL-PDT, Prof. Calzavara-Pinton and coworkers presented on an indirect statistical method (Bucher's indirect comparison) to compare these two field-directed approaches. In the presented study, an adjusted indirect comparison revealed that mild, moderate or mild and moderate AK lesions treated with MAL-DL-PDT were more than four times more likely to have complete response than lesions treated with DHA. Christoffer Nielsen from Copenhagen, Denmark, reported on a sequential combination study of 5-fluorouracil (5-FU) and MAL-DL-PDT for AK on the dorsum of the hands. Overall clearance rate for DL-PDT alone was already $46 \%$, and increased to $58 \%$ in combination with 5-FU. Since the reporting of the two COMET-trials in 2014 and 2015 performed in Australia and Europe, which were the basis for the registration of MAL in combination with daylight, several trials have looked for clearance of $\mathrm{AK}$ in the long-term and histologic effects. Dr. Fargnoli presented her trial with 12-months efficacy data in 34 AK patients who have received MAL-DL-PDT vs. conventional PDT (c-PDT) in a single session. The 12-months recurrence rates did not differ significantly (DL-PDT 10\%, c-PDT 8\%) and efficacy outcomes of the two treatments were similar for scalp AK lesions and no safety issues were documented during follow-up. Dr. Beni Grinblat from Sao Paulo, Brazil reported on his clinical trial where the histological impact of DL-PDT was studied on $\mathrm{AK}$ and field cancerized areas close to the visible lesions. DL-PDT with MAL reduced the histological parameters of keratinocyte atypia in AK treated by $82 \%$ and improvement of atypia extension was observed in field cancerized areas in $52 \%$.

\section{Plenary Session IV: DL-PDT: How I Do It}

Dr. Colin Morton from Stirling, Scotland, presented on a recently published consensus paper dealing with the practical approach to the use of DL-PDT (Fig. 2). DL-PDT is suitable for patients with AK on face and scalp, lesion severity should be grade I or II AKs or actinic field damage.

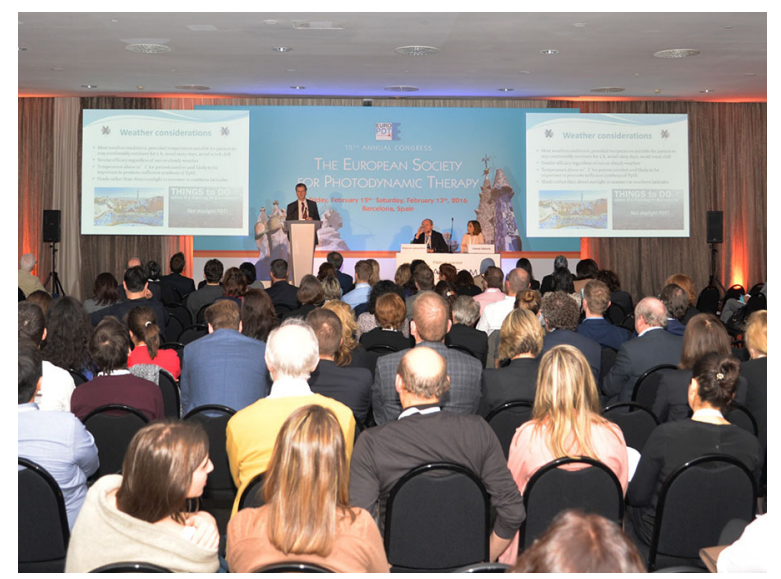

Fig. 2 Audience listening to talk of Dr. Colin Morton, Stirling, Scotland and Board Member of EURO-PDT on the recently published European Consensus on practical approach to the use of daylight-PDT 
Application of a SPF $>20$ sunscreen (non-physical protectant) is recommended to all sun exposed areas 15 min before MAL cream is used. Daylight exposure should commence within 30 min with an exposure time of $120 \mathrm{~min}$. Relevant outdoor conditions are not limited, besides temperature above $10^{\circ} \mathrm{C}$ and no rain. Afterwards any remaining MAL cream should be washed off and the patient should protect their skin for at least 24 h. Prof. Christophe Bedane, Limoges, France compared MAL DL-PDT with MAL PDT using blue light in a small clinical trial with 26 patients with AK grade I. Regarding response rates there was no significant difference after 6 months, but pain was significantly lower for DL-PDT (visual analog scale VAS 2) vs. VAS 7 for blue light. Ana Julia Garcia-Malinis from Huesca, Spain revealed another important aspect of DL-PDT. In her survey, 50 patients receiving MAL DL-PDT (procedures including curettage and MAL application prior to daylight exposure) were monitored. Both mean (6 min) and average (5 min) time for preparing for DL-PDT in each individual patient fitted nicely in the routine clinical practice setting. Prof. Sally Ibbotson from Dundee, Scotland reported on her 3-yrs experience with DL-PDT, and pointed out the extremely well tolerated side effects, especially pain, with a median pain score of 1 (range $0-8$ ) in her patients $(n=60)$. Since patients have had experience with various treatments, including c-PDT, DL-PDT now offers with its favourable results an efficient way to streamline PDT services. In the final talk that evening, Prof. Hans Christian Wulf from Copenhagen, Denmark, the inventor of the DL-PDT procedure, asked himself the question if other lamp types like slide or overhead projectors, white or red LEDs or natural daylight in a greenhouse can be as sufficient as DL-PDT. Based on the protoporphyrin IX (PPIX) weighted fluence rate, $5000 \mathrm{~lx}$ seemed to be efficient for complete activation of PPIX, only white LED needed $12,0001 x$. In the greenhouse, data was close to natural DL, with the advantage that the window glass prevents sunburn.

The evening continued with finger food, tapas and wine at the posters. Eight presentations were given and the three best were rewarded by a poster prize sponsored by photonamic, Reinbek, Germany. The third prize was received by Oscar Muňoz Moreno-Arrones from Madrid, Spain who presented 6 patients with a naevus sebaceous treated with PDT. Although there was no complete clearance of the lesions, clinical and cosmetic improvement was achieved. The second prize was awarded to Yik Weng Yew from Singapore. His group treated truncal acne in 15 patients with 5\% aminolevulinic acid for $3 \mathrm{~h}$ under occlusion, followed by illumination with red light $(37 \mathrm{~J} /$ $\mathrm{cm}^{2}$ ) in a single session. 12 weeks later, a $64 \%$ reduction of inflammatory and $24 \%$ of non-inflammatory lesions was still present. The first prize also went to Spain, Dr. García-Malinis from Huesca used MAL-PDT for 43 patients with chondrodermatitis nodularis helicis (Fig. 3). Around $74 \%$ of

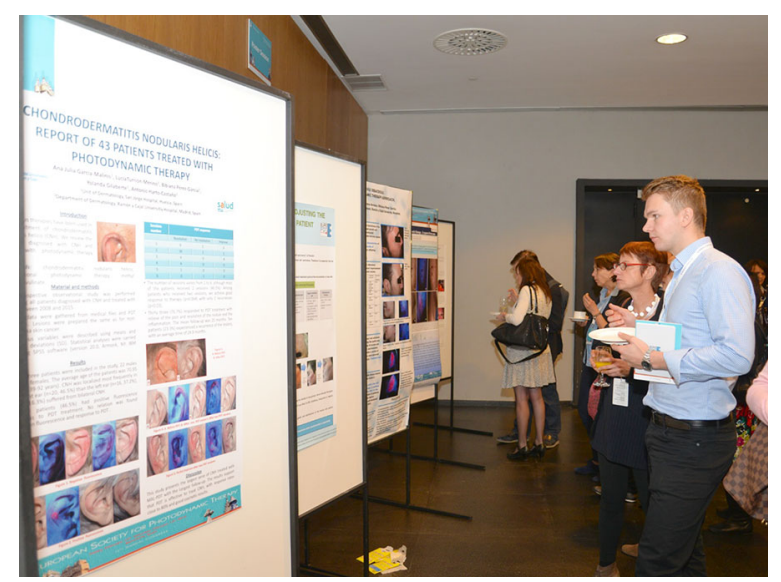

Fig. 3 Poster viewing session at the 15th Annual Congress of EURO-PDT in Barcelona, Spain. The Award-winning poster of Dr. García-Malinis on her study of MAL-PDT for Chondrodermatitis nodularis helicis is on the left 
patients (mean follow up of 20 months) showed pain relief and resolution of the inflammatory nodule.

\section{DAY 2}

\section{Plenary Session V: AK Prevention}

The next morning continued with a focus on AK prevention. Dr. Claas Ulrich from Berlin, Germany outlined the importance of raising awareness of UV-induced cancers especially in outdoor workers, since within the EC there are at least 9.1 million workers constantly exposed to solar radiation. Thus, risk of non-melanoma skin cancer is obvious and, therefore, screening and preventive programs within the whole EC make sense. Dr. Katrine Togsverd-Bo from Copenhagen, Denmark demonstrated that prophylactic PDT in organ transplant recipients under constant immunosuppression delays onset of AK significantly. After 3 years, PDT-treated areas developed in 28\% AK, whereas untreated areas showed in 63\% $\mathrm{AK}$ (Fig. 4).

\section{Plenary Session VI: BCC}

Prof. Uwe Paasch, Leipzig, Germany then took the opportunity to speak on the collaborative work together with Prof. Merete Hædersdal from Copenhagen, Denmark, pretreating high-risk BCC $(n=32)$ with ablative fractionated lasers (AFXL) prior to MAL-PDT. Clinical cure rates after 3 months were $100 \%$ for AFXL-PDT vs. $88 \%$ for c-PDT. However, histology revealed no difference regarding tumour clearance after 12 months (63\% vs. $56 \%)$. Prof. Celeste Brito from Braga, Portugal then presented her retrospective study on more than 550 patients with NMSC receiving

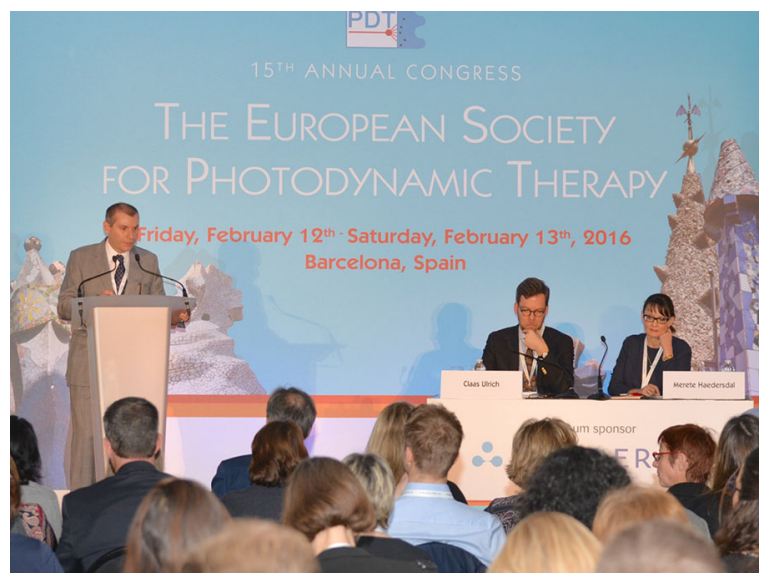

Fig. 4 Prof. Luis Torezan, Sao Paulo, Brazil presenting first clinical data on MAL-PDT split-scalp study for AK enhanced by topical pretreatment with the vitamin $\mathrm{D}$ analogue calcipotriol

MAL-PDT over 10 years. During the average follow-up period of 5.5 years, lesion-based cure rates were $99.5 \%$.

\section{Plenary Session VII: Skin Rejuvenation and Other Indications}

Santi Nonell, Professor of Chemistry of the University of Barcelona then took the audience to a new interesting therapeutic field utilizing PDT for antimicrobial purposes. He presented newly developed photosensitizers, some in combination with silver nanoparticles which work well on both gram-positive and -negative bacteria. Prof. Yolanda Gilaberte then shared the results of the first multicenter, randomized controlled clinical trial on MAL-PDT for onychomycosis. Three sessions of $40 \%$ urea followed by c-PDT with MAL on diseased nails were performed and evaluated after 36 weeks. Clinical cure was observed in almost $20 \%$ of patients in the PDT group and only $6 \%$ of controls. No significant side effects were reported.

In the final session, aesthetic aspects of PDT were in focus. Prof. Peter Bjerring from Vejle, 
Denmark, Dr. Matteo Tretti Clementoni from Milan, Italy and again Prof. Arne Gerber demonstrated that even DL-PDT is a powerful tool in reversing clinical signs of photoageing. Combination with fractionated lasers, microneedling, or sandpaper application are possible and side effects like post treatment erythema can be controlled by topical application of brimonidine tartrate $0.33 \%$ gel. Then Prof. Sigrid Karrer, Regensburg, Germany presented a randomized study comparing scalp nerve blocks, intravenous analgesia and cold air analgesia, and cold air analgesia alone for scalp and forehead AK treated with MAL-PDT. Scalp nerve blocks significantly reduced VAS pain (2.1) but no difference was found in i.v. analgesia and cold air and cold air alone (VAS 7.3 vs. 8.4). In a small study, Dr. Dario Fai from Lecce, Italy reported on the use of MAL DL-PDT in actinic cheilitis. Seven out of eight patients reached complete response after 2 PDT sessions 7-14 days apart. DL-PDT has also been used in the treatment of cutaneous leishmaniasis. Prof. Claes Enk from Jerusalem, Israel demonstrated an $88.9 \%$ cure rate in patients receiving repetitive DL-PDT once weekly until clinical and microbiological cure either with daylight exposure in the hospital garden or at home. The final presentation was given by Prof. Ann-Marie Wennberg from Gothenburg, Sweden. She showed data from a multicentre trial in 153 patients with inflammatory and non-inflammatory acne lesions. A concentration of MAL with $80 \mathrm{mg} / \mathrm{g}$ was used. MAL-PDT significantly decreased the number of inflammatory lesions ( $43.8 \%$ vs. $26.6 \%$ in the vehicle group), and no serious adverse events were reported.

During the closing ceremony, Prof. Braathen, Dr. Morton and Prof. Szeimies from Recklinghausen, Germany awarded the three winners of the best oral presentations sponsored by Galderma International, Lausanne, Switzerland. The third prize received Dr. Martina Hund from Berlin, Germany for her presentation on microneedling assisted DL-PDT for AK. The second prize recognized Beni Grinblat and his work on histologic assessment of DL-PDT for AK. And the winner of the best oral presentation was Christopher Nissen from Denmark reporting on the sequential combination of 5-FU and DL-PDT with MAL. Prof. Braathen then thanked all speakers for their excellent presentations and the audience for active participation in the discussion and reminded all of the European Clinical Cases Challenge on PDT Competition were cases including color pictures now can be submitted (open until December 31st 2016; for further information, go to http://www. europdtcontest.org).

\section{ACKNOWLEDGMENTS}

The article processing charges for this publication were funded by Galderma. All named authors meet the International Committee of Medical Journal Editors (ICMJE) criteria for authorship for this manuscript, take responsibility for the integrity of the work as a whole, and have given final approval for the version to be published.

Disclosures. Lasse R. Braathen is President of EURO-PDT. He has received travel support to scientific congresses from Galderma. Colin A. Morton has been on advisory boards for AbbVie, Almirall S.A. and Leo Pharma; has been an investigator for Biofrontera AG and Leo Pharma; and has received travel support from Almirall S.A., Galderma and Leo Pharma. Rolf-Markus Szeimies is Vice-President of EURO-PDT. He is the member of advisory 
boards for Almirall, Biofrontera, Galderma, ISDIN, Leo Pharma, photonamic, and Pierre-Fabre; has received speaker honoraria and participated in clinical trials for the aforementioned companies. This article does not contain any new studies with human or animal subjects performed by any of the authors.

Compliance with Ethics Guidelines. This article does not contain any new studies with human or animal subjects performed by any of the authors.
Open Access. This article is distributed under the terms of the Creative Commons AttributionNonCommercial 4.0 International License (http://creativecommons.org/licenses/by-nc/4. $0 /$ ), which permits any noncommercial use, distribution, and reproduction in any medium, provided you give appropriate credit to the original author(s) and the source, provide a link to the Creative Commons license, and indicate if changes were made. 